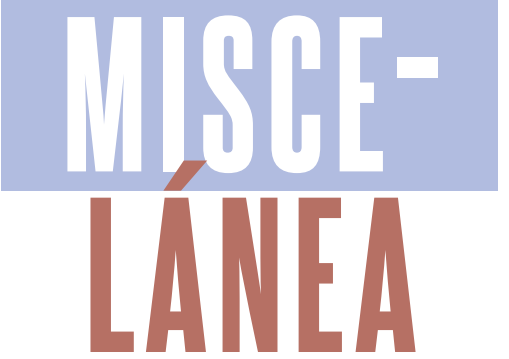

J.Xavier

Velasco:elsueño

dehacer cine

\section{Fernando Carrillo Finck}

n la escena internacional, el cine mexicano ha logrado el reconocimiento de gran parte de la crítica gracias a trabajos con concepciones renovadas del llamado séptimo arte. Los proyectos que surgen a lo largo del territorio evidencian la pluralidad de propuestas formales que integran la cinematografía nacional. Desde el ámbito xalapeño en particular, la obra de J. Xavier Velasco se presenta como una de las más sólidas, producto de las experiencias profesionales del cineasta.

J. Xavier Velasco nació en Xalapa en 1979. ${ }^{1}$ A pesar de haber estudiado la carrera de Física en la Benemérita Universidad de Puebla, desde este periodo universitario tuvo un acercamiento más serio al cine a través de talleres y también colaborando como actor en diversos cortometrajes estudiantiles. Tras licenciarse regresó a Xalapa para dedicarse de lleno al trabajo audiovisual y en el 2002 dirigió su primer cortometraje formal, Dulce Lola, que contó con las actuaciones de Verónica Segura (Star Wars: El ataque de los clones) y los reconocidos actores y direc- tores de teatro Martín Zapata, Jorge Castillo y Manuel Domínguez.

Dos años más tarde, en su ciudad natal, se asoció con quien esto escribe y con Alejandro Voorduin para coescribir y codirigir el largometraje independiente El que habita las alturas protagonizado por Arcelia Ramírez, Ana Layevska, Susana Saldaña, Martín Zapata y Rodrigo Angoitia y producido por Oscar García. Este proyecto marcó un antes y un después en la naciente escena cineasta xalapeña al conjuntar a diversos jóvenes talentos tanto detrás como delante de cámara. Cabe mencionar que fue la última película en la que participó la emblemática actriz xalapeña Lupita Balderas.

En 2005 realizó el detras de cámara de la película Apocalypto, dirigida por el actor Mel Gibson. En los siete meses que duró el rodaje tuvo oportunidad de formarse y conocer a quien posteriormente sería su estrecho colaborador como cinefotógrafo de cabecera: Felipe Pérez-Burchard. A partir de esa experiencia trabajó en diversas producciones extranjeras tanto en cine como en comerciales, además de dirigir algunas películas para televisión.

En 2010 realizó el cortometraje de ciencia ficción titulado $G$, con el que obtuvo gran éxito tras volverse viral en Vimeo y recibir el reconocimiento de Vimeo Staff Pick, llamando la atención de diversos productores en Estados Unidos. Ese mismo año ganó el premio de apoyo a la realización de cortometrajes del Instituto Mexicano de Cinematografía, con el cual llevó a cabo el corto llamado Juan y la Borrega (2011), inspirado por la ola de violencia que golpeó a México, y en particular al estado de Veracuz. Este trabajo constituyó un considerable avance al ser rodado con un crew profesional y en película de $35 \mathrm{~mm}$, además de que contó con actores de renombre como Carlos Aragón, Edgar Vivar y su colaborador recurrente, Manuel Domínguez.

Juan y la Borrega se estrenó en el Festival Internacional de Cine de Guadalajara y fue seleccionado en más de treinta festivales internacionales como el AFI Fest y el Palm Springs Short Film Festival. Los elementos fantásticos se encuentran presentes a lo largo de la filmografía de J. Xavier Velasco, quien ha sido considerado uno de los talentos veracruzanos emergentes en materia cinematográfica. El manejo de la atmósfera y la estética son especialmente notables, así como su trabajo con actores.

Resulta notoria la madurez de este trabajo tanto en el uso de la narrativa audiovisual como en la dirección actoral, que no pasaron desapercibidos pues resultó nominado al Ariel para Mejor Cortometraje de Ficción en el 2012. En ese año fue contactado por Robert Fontaine -actor, guionista y director estadounidense-, quien lo invitó a trabajar como productor $y$ director de segunda cámara en su largometraje Mi América (2015). Este filme relata diferentes historias en un pequeño pueblo del estado de Nueva York, donde se muestra un universo de problemáticas sociales, principalmente los crímenes de odio en contra de la comunidad latina. Mi América se filmó en el estado de Nueva York y fue adquirida para su distribución por нво.

Al volver del rodaje de $M i$ América, Velasco filmó el cortometraje Zerch (2015) y una vez más recibió apoyo por parte de Imcine, en esta ocasión, para la posproducción. Al tratarse de una historia de lo que se conoce como "horror lovecraftiano", es decir, inspirado por las historias del legendario escritor de "horror cósmico”, Howard Phillips Lovecraft, Zerch tuvo gran éxito en festivales 


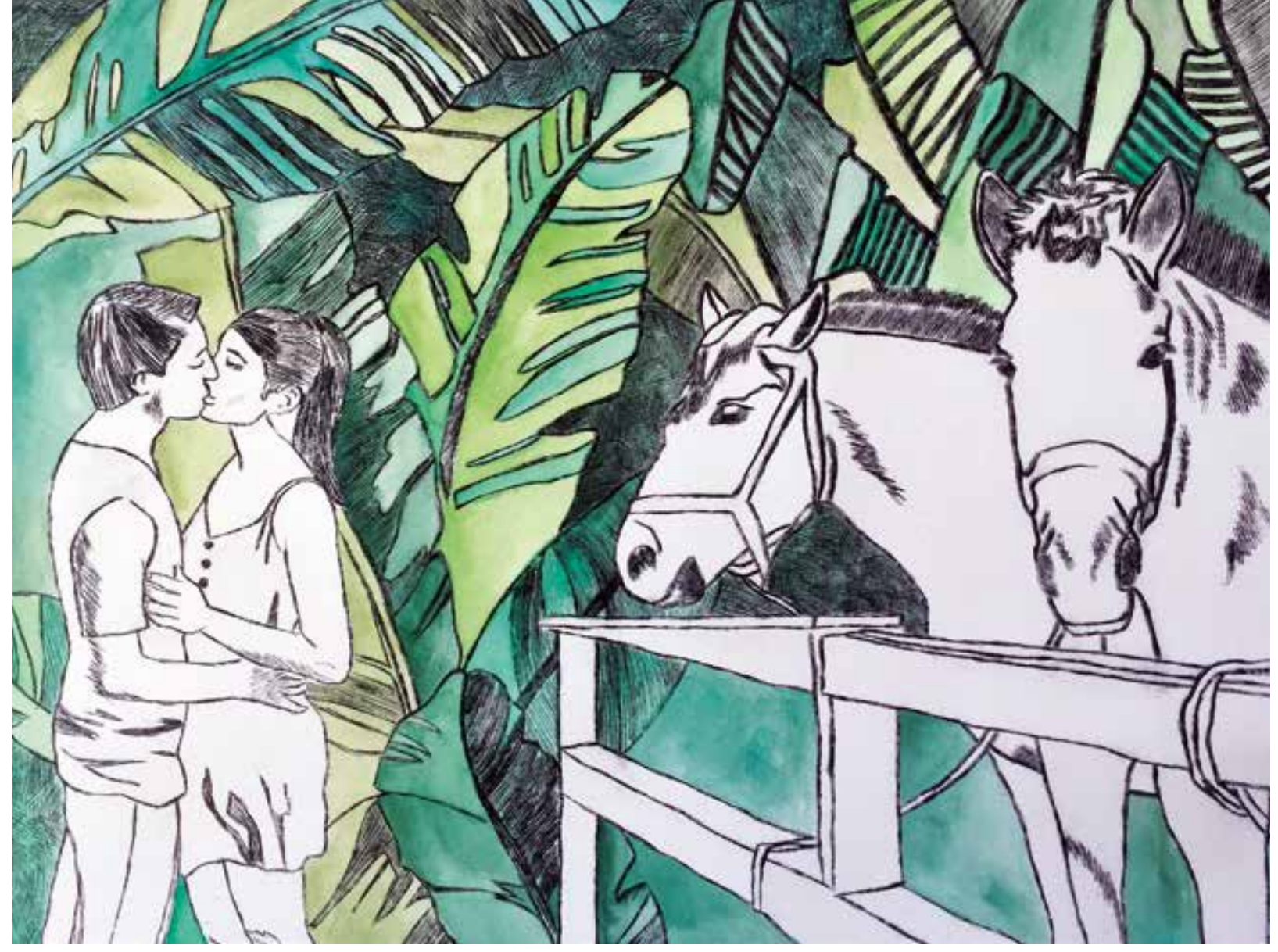

Ellos y nosotros

especializados en cine de género fantástico e, incluso, centrados en las historias inspiradas por la obra de Lovecraft. Una vez más el actor Manuel Domínguez representó a un hombre poseído por un monstruo de otro mundo que manipula a su pareja sentimental, interpretada por Daniel Villar.

Velasco radica desde 2014 en la ciudad de Nueva York, donde continúa su desarrollo como director en diversos proyectos y comerciales de moda además de colaborar como productor en largometrajes y proyectos audiovisuales $y$, eventualmente, como cinefotógrafo. En 2017 recibió un Emmy regional por su trabajo de fotografía en el documental From the Streets to the Stage: The Journey of Fredrick Davis (2017), para el canal PBS.

Actualmente se encuentra terminando su más reciente cortome-
En 2010 realizó el cortometraje de ciencia ficción titulado $G$, con el que obtuvo gran éxito tras volverse viral en Vimeo y recibir el reconocimiento de Vimeo Staff

Pick, llamando la atención de diversos productores en Estados Unidos.

traje: Above and Below the Waves, filmado en Nueva York y próximo a estrenarse, además de desarrollar su tan esperada ópera prima El ojo de los días, un thriller psicológico situado en la ciudad de Tijuana y protagonizado por Joaquín Cosío y Miguel Rodarte, cuyo guion está basado en la novela innédita Hasta aquí el desierto del escritor juarense César Silva Márquez.

No queda más que esperar que pronto dirija largometrajes, los cuales sin duda poseerán las cualidades que ha mostrado en sus cortos. LPyH

Nota

${ }^{1}$ Para ver sus trabajos y seguirle la pista se puede visitar su sitio web www.jxaviervelasco.com

Fernando Carrillo Finck (Xalapa, 1978) es guionista y director audiovisual. Imparte clases de cine, televisión $y$ guion en diversas universidades. 